\title{
Circulating microRNAs Signature as a promising epigenetic diagnostic biomarker of equine osteoarthritis
}

Aya M. Yassin ( $\sim$ ayamohye@cu.edu.eg )

Cairo University

Huda O. AbuBakr

Cairo University

Ahmed I. Abdelgalil

Cairo University

Omar A. Farid

National Organization for Drug Control and Research

Adel M. EL-Behairy

Cairo University

Eman M. Gouda

Cairo University

\section{Research Article}

Keywords: Osteoarthritis, GAGs, CS, epigenetic, miR146b, miR27b TRAF-6, COL10A1

Posted Date: March 3rd, 2022

DOI: https://doi.org/10.21203/rs.3.rs-1398719/v1

License: (1) This work is licensed under a Creative Commons Attribution 4.0 International License.

Read Full License 


\section{Abstract}

Background: One of the most orthopedic problems seen in the equine is osteoarthritis (OA). The present study tracks some biochemical, epigenetic, and transcriptomic factors along different stages of monoiodoacetate (MIA) induced OA in donkeys in serum and synovial fluid. The aim of the study was the detection of sensitive noninvasive early biomarkers.

Methods: OA was induced by a single intra-articular injection of $25 \mathrm{mg}$ of MIA into the left radiocarpal joint of nine donkeys. Serum and synovial samples were taken at zero-day and different intervals for assessment of total GAGs and CS levels as well as miR 146b, miR 27b, TRAF-6, and COL10A1 gene expression.

Results: The results showed that the level of total GAGs and CS increased in different stages of OA. The level of expression of both miR-146b and miR-27b were upregulated as OA progressed and then downregulated at late stages. TRAF- 6 gene was upregulated at the late stage while synovial fluid COL10A1 was over-expressed at the early stage of OA then decreased at late stages $(P<0.05)$.

Conclusions: In conclusion, both miR146b and miR-27b together with COL10A1 could be used as promising noninvasive biomarkers for the very early diagnosis of $\mathrm{OA}$.

\section{Background}

Osteoarthritis (OA) as one of the most heterogenous prevalent degenerative joint diseases, is of major concern for human health. It is also one of the most common orthopedic problems seen in horses [1]. Clinical signs of disease are lameness, joint swelling, pain on flexion, or reduced activity, and, with time, these symptoms lead to structural joint alterations. Degradation of articular cartilage is a consequence of its poor capacity to repair and withstand the cyclic trauma of athletic activity, and this is exacerbated with aging [2]. In the clinical routine, there are no available sensitive and specific blood biomarkers that can detect the initial stages of the disease or predict the future development of OA. Consequently, there is great interest in the identification of new markers[3].

Genetic variation studies have identified many candidate genes in defined radiographic cases with small effects on the overall risk of OA. However, these genes cannot fully and clearly explain the strong genetic component which is implicated in OA onset and progression[4]Therefore, other mechanisms have been involved such as epigenetics. Epigenetics refers to the covalent modification of DNA, protein, or RNA without altering their primary sequences, resulting in changes to the function and/or regulation of these molecules. Mostly every aspect of biology is influenced by epigenetics. The most studied epigenetic factors are DNA-methylation and non-coding RNAs.[4,5]

Chondrocytes in cartilage function normally to produce and secret the extracellular matrix proteins to maintain cartilage integrity[6]. During the disease conditions, the chondrocytes change their behavior, they become autophagy, overexpress the hypertrophy markers as COLX, and secrete the inflammatory 
cytokines or small fragments of nucleic acid as microRNAs (miRNAs) to promote cell degeneration and apoptosis[7,8].

MicroRNAs (miRs) are small non-coding RNAs of approximately 22 nucleotides in length that can silence gene expression by binding to a complementary sequence on the 3 ' untranslated regions (3'-UTR) of target mRNAs resulting in translational repression or target degradation $[9,10]$. miRNAs can be found intracellularly or extracellularly, circulating in virtually any biological fluid in a remarkably stable manner[11]. Many reviews mentioned the involvement of miRNAs in normal conditions of the articular cartilage (osteoblastogenesis and osteoclastogenesis, and chondrogenesis) as well as in the pathological conditions (cartilage degradation, synovial inflammation, and OA progression) [12,13 ,14].Many miRNAs, including miR-101[15],miR-181c[16], miR-675[17], miR-770[18], miR140[19],miR-146a [20], miR-27a[21], miR-122[22], miR 130a [23], miR-15a[24], and miR-127-5P[25]have been reported to be engaged to OA pathogenesis through regulation of cartilage homeostasis, chondrocyte metabolism, inflammatory responses, as well as proteolytic enzyme activity.

Because biological fluids are generally obtainable through minimally invasive techniques, circulating miRNAs are attractive candidates for disease diagnosis, monitoring, and prognostication [26,27]. Circulating miRNAs have been investigated in several studies, Murata et al. (2010) performed an analysis on differentially expressed miRNAs in the synovial fluid and the plasma of patients with OA, rheumatic arthritis (RA), and healthy controls. They concluded that plasma miR-132 levels could be a significant marker to distinguish individuals with OA/RA from healthy controls[28]. Similarly, Li et al. (2016) identified OA-specific miRNAs in synovial fluid. They found miRNAs 23a-3p, 24-3p, 27a-3p, 27b-3p, 29c-3p, 34a-5p, and 186-5p differentially regulated in early and late phase OA[29] . Ntoumou et al. (2017) found 279 miRNAs differentially expressed in serum of osteoarthritic conditions. Further, they validated their preliminary findings and showed 3 signature miRNAs; $140-3 p$, 33b-3p, and 671-3p down-regulated in OA. These miRNAs are known to be involved in several molecular pathways including Wnt, ErbB, TGF-beta[30]. Synovial fluid miRNAs as miR-29b3p and miR-140 were suggested as $\mathrm{OA}$ biomarkers and have shown a strong correlation with radiographic knee OA severity[31,32]. Equine miRNAs have been studied in healthy tissues [33,34] and different diseases; osteochondrosis, rhabdomyolysis, and insulin resistance[35,36,37]. Castanheira et al. (2021) revealed 22 differentially expressed sncRNAs in equine synovial fluid as well as validated that miR-223 was significantly reduced in early osteoarthritis and miR-23b, let-7a-2, snord96A, and snord13 were significantly upregulated[38]. MiR-146b has been reported to play a role in the regulation of cell differentiation, proliferation, and migration in various tumor cells $[39,40]$. miR-146b has also been identified to be involved in the chondrogenic differentiation of human bone marrow-derived SSCs, through modulation of SOX5 [41].

MiR-27b, chondroprotective miRNA, is targeting MMP13 and negatively correlated with its expression. the activated NF-KB could up-regulate the expression of MMP-13 but act as a negative regulator of miR-27b in promoting chondrocytes degradation [42]. 
One of the main hindering issues in the development of efficient therapeutic regimes for OA is the inability to detect and track the early pre early pre-clinical changes of the disease[43]. Profiling the synovial fluid within the affected joint at the early stages of the disease may provide new insights into pathological changes occurring during $O A$ initiation and progression, and help develop new therapeutic approaches; however, it is the most difficult to assess, because of the invasive techniques involved with its collection. Meanwhile, the serum is easily accessible because it can be extracted from the body with minimally invasive techniques as well as the site of much of the body's metabolism, and therefore many of the changes that might occur with OA can be represented by serum biomarkers. The current study, based on our previous work[1], is aiming to track the biochemical, epigenetic, and transcriptomic changes along the different stages of OA in serum and synovial fluid in MIA-induced OA donkeys for the establishment of noninvasive biomarkers for early diagnosis and prognosis of $\mathrm{OA}$.

\section{Methods}

\section{Ethical Statement}

This animal experiment followed the guidelines developed by the American Psychological Association (APA) for the ethical conduct of care and use of animals and approval was obtained from CU-IACUC with No. $(\mathrm{CU} / \mathrm{II} / \mathrm{F} / 4 / 16)$.

\section{Experimental study design:}

Based on our previous study and experimental design of equine osteoarthritis that was recently published by Yassin et al. (2020)[1], The current study was conducted for investigation of some biochemical, transcriptomic, and epigenetic biomarkers in synovial fluid and serum samples. Synovial fluid samples were collected from the left radiocarpal joint and blood samples were collected from the left jugular vein on plain tubes then centrifuged at $1500 \mathrm{xg}$ for $15 \mathrm{~min}$. Both samples were kept at $-80^{\circ} \mathrm{C}$ for further analysis.

\section{Biochemical analysis:}

The concentration of total glycosaminoglycans (GAGs) and chondroitin sulfate (CS) was assessed by High-performance liquid chromatography (HPLC) at Day $0,1^{\text {st }}$ week, $1^{\text {st }}$ month, $2^{\text {nd }}$ months, $3^{\text {rd }}$ months, $5^{\text {th }}$ months, and $7^{\text {th }}$ months post-MIA-injection as modified according to [44]. Briefly; serum and synovial samples were dissolved with deionized water: acetonitrile (80:20\%) then centrifuged at $5000 \mathrm{rpm}$ for $10 \mathrm{~min}$. The clear supernatants were ready for analysis by the isocratic HPLC system (Agilent 1200 Series equipped with the computerized solvent delivery system and UV detector, Santa Clara, CA, USA) using Supelco Kromasil NH2 silica gel column ( $5 \mu \mathrm{m}$ particle size, pore size $100 \mathrm{~A}$ ) with flow rate $1.5 \mathrm{ml}$ 


\section{Transcriptomic and epigenetic quantitative real-time polymerase chain reaction (qRT-PCR) of miRNAs and their target genes :}

Total RNA and miRNAs in serum and synovial fluid samples were extracted using miRNeasy Mini Kit (Qiagen, Hilden, Germany cat. no. 217004) according to the manufacturer's protocol with Serum/Plasma Spike-In Control for data normalization (Qiagen, cat. no. 219610). Total RNA purity and concentration were obtained using a nanodrop ND-1000 spectrophotometer. The isolated RNA was used for CDNA synthesis of target genes using Revert Aid Reverse Transcriptase (Thermo Scientific, Cat. No. EP0441, USA) according to the provided guidelines. Real-time PCR (qPCR) was performed in a total volume of 20$\mu \mathrm{l}$ using a mixture of $1 \mu \mathrm{l} \mathrm{cDNA}, 0.5 \mathrm{mM}$ of each primer (Table 1), iQ SYBR Green Premix (Thermo Scientific, Cat. No. K0221, USA).

TaqMan ${ }^{\circledR}$ microRNA Reverse Transcription kit was used for miRNA reverse transcription of the isolated RNA using (Applied Biosystems, cat. no.4366596) as manufacture protocol. The sequence-specific RT primer was provided in each TaqMan ${ }^{\circledR}$ microRNA ready-made assay (sequence-specific primers/probes); hsa-miR-146b (assay ID: 001097) and hsa-miR-27b (assay ID:000409). Accurate and reliable results were obtained through normalization of RT-qPCR data with spike-in control cel-miR-39 (assay ID:000200). Taqman Real-time PCR (qPCR) was performed in a total volume $20-\mu$ l using a mixture of $1.33 \mu \mathrm{l} \mathrm{cDNA,10}$ ul TaqMan ${ }^{\circledR}$ universal PCR Master Mix II, No UNG (2X) (Applied Biosystems, Belgium, cat. no. 4440043),1 $\mu \mathrm{l}$ TaqMan MicroRNA Assay Mix. ). PCR amplification and analysis of total and miRNAs expression were achieved using Bio-Rad iCycler thermal cycler and the MyiQ real-time PCR detection system. Each assay includes triplicate samples for each tested cDNAs and no-template negative control, the expression relative to the control is calculated using the equation $2^{-\Delta \Delta C T}[45]$.

Table 1

Primer sequences of reference, COL10A1, and TRAF- 6 genes of Equus asinus: 


\begin{tabular}{|llll|}
\hline Target genes & Accession no. & Sequence (5' to 3') & Product size \\
\hline $\begin{array}{l}\text { B-actin (ACTB) as } \\
\text { (reference gene) }\end{array}$ & XM_014835097.1 & F:5'CGACATCCGTAAGGACCTGT3' & 192bp \\
\hline COL10A1 & XM_014866148.1 & F: 5'GGAGAAAGGGGTTTCTCTGG3' & 183bp \\
& & R:5'ACCATTGTTTCCAGGCACTC3' & \\
\hline TRAF-6 & XM_014851023.1 & F:5' ATCCCACGGAACCCAAAA 3' & 175bp \\
& & R:5' CCCCAGTATCAGTGCTTCGT 3' & \\
\hline
\end{tabular}

\section{Statistical analysis:}

The obtained data were statistically analyzed using the One-Way ANOVA Statistics, version 24.0 software (SPSS Inc., Chicago, IL, USA). Polynomial contrasts, post-hoc Duncan, and descriptive statistics were performed. The level of significance was set at $p \leq 0.05$. The represented values are given as a standard error of the mean (SEM).

\section{Results}

\section{Biochemical findings of total GAGS and CS concentrations in serum and synovial fluid:}

In serum and synovial fluid samples; the concentration of total GAGs recorded the highest significant concentration at the $3^{\text {rd }}$ month post-MIA injection (Figure 1,2).

The concentration of CS in serum was significantly increased only at the $5^{\text {th }}$ and $7^{\text {th }}$ month (Figure $3 A$ ), while in the synovial fluid; CS showed an irregular significant increase from day 0 with the highest significant level at the $3^{\text {rd }}$ month (Figure 3B ).

\section{Transcriptomic and epigenetic qRT-PCR of miRNAs and their target genes findings:}

\section{Expression levels of miR-146b and miR-27b:}

In serum, the expression level of miR-146b was significantly up-regulated immediately at 1 week, 1 month, 3 months after MIA injection by $3.1,6.7$, and 2.26 folds, respectively. While at the $2^{\text {nd }}, 5^{\text {th }}$, and $7^{\text {th }}$ months; the expression level of miR-146b was not detected (Figure 4A). In the synovial fluid sample, miR-146b was recorded to be significantly up-regulated starting from the first month till the $3^{\text {rd }}$ month by $6.1,4.6$, 
and 1.76 folds respectively. While at the $5^{\text {th }}$ and $7^{\text {th }}$ months the expression of miR-146b was significantly down-regulated to 0.13 and 0.16 folds, respectively (Figure 4B). Herein, the maximum significant expression of serum and synovial fluid samples for miR-146 was observed in the $1^{\text {st }}$ month.

The expression level of miR-27b in serum and synovial fluid samples was investigated throughout the experiments. The obtained results from serum samples showed that miR-27b was significantly upregulated rapidly 1 -week post-MIA injection till the third month by $3.6,4.8,2.1$, and 3.9 folds, respectively. Moreover, our data revealed that miR-27b expression was not detected at the $5^{\text {th }}$ month and the $7^{\text {th }}$ month (Figure 5A). While in the synovial fluid samples, the miR-27b up-regulation was identified significantly only on the $1^{\text {st }}$ and the $2^{\text {nd }}$-month post-injection by 4.5 and 4.4 fold, respectively. The $1^{\text {st }}$ week, $33^{\text {rd }}$ month, $5^{\text {th }}$ month, and the $7^{\text {th }}$ month exhibited significant down-regulation to $(0.7,0.9,0.11$, and 0.23$)$ folds, respectively (Figure 5B). For serum and synovial fluid samples, the maximum significant upregulation for miR-27b was observed in the $1^{\text {st }}$ month

\section{The expression level of TRAF- 6 and COL10A1 genes:}

Our study showed that the expression of serum TRAF- 6 was significantly up-regulated by 471.8 fold at the third month while significant down-regulation at $1^{\text {st }}$ month, $2^{\text {nd }}$ month, and $5^{\text {th }}$ month by $0.853,0.88$, and 0.32 folds, respectively. Whereas, its expression wasn't detected at the $2 n d$ and the $7^{\text {th }}$ month (Figure 6A). Regarding synovial TRAF-6 expression level, it was up-regulated significantly at the $2^{\text {nd }}$ and $5^{\text {th }}$ month post -MIA injection by 1.4 fold and 1.1 fold respectively and down-regulated significantly at the $3^{\text {rd }}$ month by 0.2 fold. While, the TRAF- 6 expression wasn't detected in $1^{\text {st }}$ week, 1 st month, and $7^{\text {th }}$ month (Figure 6B).

In serum samples, COL10A1 was observed to be significantly up-regulated at the $2^{\text {nd }}, 3^{\text {rd, }}$ and $5^{\text {th }}$ months post-MIA injection by $1.5,9.5$, and 2.6 folds, respectively. Also, it was noticed that the periods of downregulation were at the $1^{\text {st }}$ month and $7^{\text {th }}$ month by 0.93 and 0.2 folds, respectively, and weren't detected at the $1^{\text {st }}$ week (Figure 7A). In synovial fluid samples, COL10A1 was immediately up-regulated following MIA injection till the $3^{\text {rd }}$ month by $34.6,35.6$, and 19.14 , respectively then it's down-regulated at the $5^{\text {th }}$ and $7^{\text {th }}$ month by 0.72 and 0.48 folds, respectively.

\section{Discussion}

Osteoarthritis is characterized by the progressive degeneration of the articular cartilage matrix resulting in the release of their components and degradation products, which can be measured biochemically to monitor disease progression [46].

In the present study, serum and synovial fluid total GAGs in MIA-induced OA donkeys increased especially by the $3^{\text {rd }}$ month, then declined at the $5^{\text {th }}$ and $7^{\text {th }}$ months. High levels of GAGs were recorded in chronic 
and acute joint diseases([47]; in synovial fluid, serum, and urine of horses with OA[48,49]. While the decline in the synovial fluid total GAGs at the $5^{\text {th }}$ and $7^{\text {th }}$ months can be attributed to the 'floor effect' which is characterized by complete cartilage worn-out and loss of joint space as shown in SF of patients with grade IV $O A[50,51]$. Also, these results came in context with our previous histopathological findings which revealed the loss of proteoglycan from the articular cartilage[1].

Concerning the findings of CS, serum CS was found to be significantly increased at the $5^{\text {th }}$ and $7^{\text {th }}$ months. In this context, serum CS was reported to be elevated in inflammatory diseases[28] and all OA patients[52]. While our results concerning synovial CS, its levels tended to be elevated throughout the experimental period without any discrimination between the early and late osteoarthritic changes. In agreement; the study on the polo horses showed that synovial CS increased and was related to the inflammatory process of joint tissues[53].

Several miRNAs have been involved in bone and cartilage homeostasis and development as well as the progression of $\mathrm{OA}$ through the modulation of osteoblastogenesis, osteoclastogenesis, chondrogenesis, synovial inflammation, and cartilage degradation[54]. Some miRNAs have been shown to exhibit antiinflammatory effects in the synovium during $O A$. miR- $146 a / b$ is considered as one of the key regulators in the NF-KBinflammatory response pathway by binding to the 3' UTR of their mRNAs targets of TRAF 6 and IRAK 1 resulting in their inhibition [55].

MiR-146b was found to share sequence similarities to miR-146a, so miR-146b might be up-regulated in $\mathrm{OA}$ and also target the pro-inflammatory mediators acting as an anti-inflammatory mediator[56].

In the present study, miR-146b was upregulated in serum at $1^{\text {st }}$ week, $1^{\text {st }}$ month, and $3^{\text {rd }}$ month, wherein synovial fluid at the $1^{\text {st }}, 2^{\text {nd, }}$ and $3^{\text {rd }}$ month while it wasn't detected at $2^{\text {nd }}, 5^{\text {th }}$ and $7^{\text {th }}$ months in both serum and synovial samples.

Overexpression of miR146 at early OA was reported in human PBMCs (peripheral blood mononuclear cells) [57], in joint of knee destabilization OA model[58], chondrocytes isolated from the human articular cartilage with OA[56]and knocked-down in mouse models[59]. Together, these miR-146 expressed in the circulating PBMCs of OA patients might contribute to the pathogenesis of OA due to its accumulation in the synovium in the early stage of $O A$ [57]. mir146b down-regulation was observed during the chondrogenic differentiation of human bone marrow-derived SSCs [56].

Regarding TRAF6 expression; our findings demonstrated the strong correlation of miR-146b expression with the expression of the TRAF6 gene after OA induction. The upregulation of miR-146b was coupled by the downregulation of TRAF6 expression in the early stage of OA all over the $1^{\text {st }}$ month in serum and synovial fluid samples. The significant up-regulated of TRAF6 expression was at the $3^{\text {rd }}$ month, the late stage of $\mathrm{OA}$, for serum, and at the $2^{\text {nd }}$ month, the early stage, for synovial fluid.

TRAF6 is considered as a critical intracellular mediator for the inflammatory pathways via playing the main role in the activation of NF-KB induced by lipopolysaccharide (LPS) /Toll-like receptor (TLR)-4 
signaling and in the resorption activity of osteoclasts[60]. Herein, the inhibition of TRAF6 brings into antiapoptotic, anti-catabolic, and anti-inflammatory effects in the chondrocytes injury model by regulating the NF-kB signaling pathway[61].

These results are in the same line with[62] who demonstrated that TRAF6 expression in RA synovium was significantly higher than that in OA synovium. Notably, overexpression of miR-146a in OA FLS decreased the expression of many inflammatory mediators, including TRAF 6, IRAK 1, COX2, IL-8, MMP13, and ADAMTS5 expression [63]. Besides, TRAF6 was upregulated in osteoarthritis patients, which indicated that it may be associated with OA [64,65] and FJOA[61] severity and progression.

Many studies refer to miR-146a as a novel target in OA by negative feedback regulation of inflammatory responses[63,66,67,68]or by promoting chondrocytes autophagy[69]. Other studies showed that miR-146 may contribute to OA pathogenesis by promoting the expression of VEGF and impairing the TGF- $\beta$ signaling pathway via targeting of Smad4[70,71]

Liu et al. (2019) reported that miR-146b was up-regulated in IL-1 $\beta$-treated chondrocytes and significantly affected cell viability and matrix gene expressions in chondrocytes. The downregulation of miR-146b profoundly inhibited caspase activation and the expression of the proteolytic enzyme. Moreover, intraarticular injection of antago-miR-146b protected mice with $\mathrm{OA}$ from cartilage degradation as well as proteoglycan loss suggesting that up-regulation of miR-146b can contribute to the development and progression of $\mathrm{OA}[41]$.

The non-expected expression pattern of miR-146 and TRAF6 at the late stage of OA can be explained by the fact that one miRNA could potentially control the expression of a few to several thousand genes. Conversely, each mRNA could be affected by multiple miRNAs[72]

Few literatures investigated the expression level of miR-27b in the OA chondrocytes and OA synovial fluid $[42,73,74,75]$. In the current study, serum, and synovial fluid mir-27b expression showed the maximum up-regulation at the $1^{\text {st }}$-month post-MIA induction of OA in donkeys and then down-regulated. In context, miR-27b was up-regulated in the synovial fluid and down-regulated in the chondrocytes following IL-1 $\beta$ stimulation which could be explained as miRNAs that respond to inflammatory stimuli (IL$1 \beta$ ) were released into the synovial fluid from synovium during $O A$ in attempts from the chondrocyte to compensate the catabolic actions [74].

Zhou et al. (2019) demonstrated that miR-27b directly inhibits chondrocyte apoptosis and, thus, ameliorates the development of RA[75]. Besides, the expression of miR-27b was sharply down-regulated, and production of MMP-13 protein was enhanced in normal or OA chondrocytes stimulated with IL$1 \beta[42]$.

We previously found that MMP-13 was highly up-regulated at the $2^{\text {nd }}$ month of MIA OA [1] despite profound up-regulation for synovial miR-27b. These unexpected expression patterns of MMP-13 and miRNA-27b could be explained as synovial miR-27b did not correspond to the MMP-13 activity in the 
synovial fluid but it was correlated to the miR-27b expressed in the chondrocytes and cannot be anticipated as a perfect one-to-one correspondence[74]. In addition, miR-27b interacts with imperfect complementation with the 3-UTR of MMP-13 mRNA and down-regulates its expression at the posttranscriptional level[42]. The context scores of miR-27b recorded low values among the microRNAs predicted to target the conserved sites in the 3-UTR of MMP-13 mRNA [42] giving the chance for other miRNAs (miR-181b[76] and miR-33a[77]) to directly or miR-145[78] indirectly increase MMP-13 expression.Further investigations are needed to clear up the correlation between synovial miR-27b and MMP-13 expression patterns.

Our results demonstrated that both serum and synovial fluid miR-27b go nearly in the same line of expression; giving an idea that serum miR-27b could be used as a predictor for the joint state and a very early biomarker for OA.

On the other hand, miR27b-3p was reported to be highly expressed in both samples collected from OA patients and rat models. Suppression of miR-27b-3p promotes the expression of the osteogenic differentiation markers while inhibiting expression of the adipogenic differentiation markers, inflammatory factors, cellular senescence of bone marrow mesenchymal stem cells (BMSCs), and alleviating OA pain in rats by demethylation of KDM4B (Lysine demethylase 4B) [79]. These observations may explain our previous finding that lameness score in donkeys has been decreased with the progression of $\mathrm{OA}[1]$

Concerning COL10A1 expression level in the current study, it increased in the $2^{\text {nd }}$, and $3^{\text {rd }}$ months with the highest level at the $1^{\text {st }}$ month after MIA injection, then downregulated at $5^{\text {th }}$ and $7^{\text {th }}$ months.

Overexpression of mir-27b upregulated the mRNA expression of the hypertrophy markers COL10A1 and the levels of COL10A1protein in human bone marrow mesenchymal stem cells [65]. miR-27b expression was found to be inversely correlated with chondrocyte hypertrophic differentiation in postnatal rat knee articular cartilage[80].

In agreement, $\mathrm{COLX}$ was significantly higher with $\mathrm{KL2}$, KL3, and $\mathrm{KL} 4$ osteoarthritic patients compared to patients with no radiographic sign of OA (KLO). Type $X$ collagen is normally not expressed in human healthy articular cartilage but its expression is detected at protein and mRNA levels in human OA cartilage [81].

Also, Fukui et al. (2008) studied the regional and zonal differences in gene expression in OA cartilage, they were demonstrated that the overall expression of COL10A1 was elevated but that expression showed significant local variation. Notably, the expression of type COL10A1 was higher in the less degenerated joint region than in the more degenerated areas and this explains our finding concerned with the significant downregulation of COL10A1 at the late stages of OA[82].

It is worth mentioning that, hypertrophy markers such as MMP-13 and type $\mathrm{X}$ collagen have been observed in several models of OA in different species as in mice [83], and in rats [84]. 
For instance, Osteoarthritis involves the dysfunction of articular chondrocytes leading to cartilage degradation through chondrocyte maturation and MMPs production[83]. During growth-plate chondrogenesis, the chondrocytes become hypertrophic with the expression of collagen type $X$, the collagen matrix is removed through the production of MMP-13, finally, it undergoes apoptosis and is replaced by bone $[85,86]$.

Despite the limitation concerning the small number of animals used in our experiment and based on our previous findings, we were able to track for the first time the changes of expression for some biochemical, transcriptomic, and epigenetic factors in serum and synovial fluid of Egyptian donkeys for the establishment of grading diagnostic biomarkers. In conclusion, based on our previous classification for the stages of OA; biochemical markers (Total GAGs and CS) showed their low efficiency in the early diagnosis or prognosis of OA since serum GAGs can't differentiate between the early and the late stages of OA and synovial GAGs can't differentiate between the normal and late OA stages. CS in serum cannot be used as an early diagnostic biomarker since it increases only at the late stage also, synovial CS cannot differentiate between the early and late OA. Conversely, transcriptomic and epigenetic factors showed a promising utility as very early noninvasive diagnostic biomarkers. Serum and synovial miR-146b showed a significant up-regulation at the very early stages of OA. Up to our knowledge, it's the first study investigated the expression level of miR-27b in serum during the different stages of OA and we suppose that it would be a promising biomarker for the very early diagnosis of OA as it was up-regulated immediately 1 week post-MIA injection and nearly showed the same expression pattern as in the synovial fluid. Synovial COL10A1 showed its early significant upregulation representing it as an early OA biomarker.

\section{Abbreviations}

OA: osteoarthritis; MIA: monoiodoacetate; GAGs: glycosaminoglycans; CS: chondroitin sulfate; SF: synovial fluid; RA: rheumatoid arthritis; MMP: matrix metalloproteinases

\section{Declarations}

\section{Author's Contributions:}

Conceptualization, A.M.Y., E.M.G, A.M.E, and H.O.A; Methodology, A.M.Y, A.I.A., O.A.F; software, A.M.Y, and H.O.A; Validation, E.M.G; Formal analysis, A.M.Y, A.I.A Writing-original draft preparation, A.M.Y.; Writingreview and editing, H.O.A, A.M.E, and E.M.G.

\section{Funding:}

This work was fully supported by the Cairo University Research Fund. 


\section{Availability of data and materials}

All data generated or analyzed during this study are included in this published article

\section{Declarations}

\section{Ethics approval}

This work was approved from CU-IACUC with No. (CU/II/F/4/16).

\section{Consent for publication}

Not applicable

\section{Competing interests}

The authors have no conflicts of interest to disclose.

\section{Author Details}

1 Department of Biochemistry and Molecular Biology, Faculty of Veterinary Medicine, Cairo University, Giza 12211, EGYPT

2 Department of Surgery, Anesthesiology, and Radiology, Faculty of Veterinary Medicine, Cairo University, Giza 12211, EGYPT

${ }^{3}$ Department of Physiology, National Organization for Drug Control and Research, Egypt

\section{References}

1. Yassin AM, AbuBakr HO, Abdelgalil Al, Khattab MS, El-Behairy AM, Gouda EM. COL2A1 and caspase3 as promising biomarkers for osteoarthritis prognosis in an Equus asinus model. Biomolecules. 2020 Mar;10(3):354.

2. Maumus M, Roussignol G, Toupet K, Penarier G, Bentz I, Teixeira S, Oustric D, Jung M, Lepage $O$, Steinberg $\mathrm{R}$, Jorgensen $\mathrm{C}$. Utility of a mouse model of osteoarthritis to demonstrate cartilage protection by IFNy-primed equine mesenchymal stem cells. Frontiers in immunology. 2016 Sep 27;7:392. 
3. Rousseau JC, Sornay-Rendu E, Borel O, Chapurlat R. Association of Circulating Micrornas With Osteoarthritis. Osteoarthritis and Cartilage. 2017 Apr 1;25:S289-90.

4. Rice SJ, Beier F, Young DA, Loughlin J. Interplay between genetics and epigenetics in osteoarthritis. Nature Reviews Rheumatology. 2020 May;16(5):268-81.

5. Van Meurs JB. Osteoarthritis year in review 2016: genetics, genomics, and epigenetics. Osteoarthritis and cartilage. 2017 Feb 1;25(2):181-9.

6. Pitsillides AA, Beier F. Cartilage biology in osteoarthritis-lessons from developmental biology. Nature Reviews Rheumatology. 2011 Nov;7(11):654-63.

7. Lotz MK, Carames B. Autophagy and cartilage homeostasis mechanisms in joint health, aging, and OA. Nature Reviews Rheumatology. 2011 Oct;7(10):579-87.

8. Nugent M. MicroRNAs: exploring new horizons in osteoarthritis. Osteoarthritis and cartilage. 2016 Apr 1;24(4):573-80.

9. Hu G, Zhao X, Wang C, Geng Y, Zhao J, Xu J, Zuo B, Zhao C, Wang C, Zhang X. MicroRNA-145 attenuates TNF-a-driven cartilage matrix degradation in osteoarthritis via direct suppression of MKK4. Cell death \& disease. 2017 Oct;8(10):e3140-

10. O'Brien J, Hayder H, Zayed Y, Peng C. Overview of microRNA biogenesis, mechanisms of actions, and circulation. Frontiers in endocrinology. 2018 Aug 3;9:402.

11. Zhao C, Sun X, Li L. Biogenesis and function of extracellular miRNAs. ExRNA. 2019 Dec;1(1):1-9.

12. Yu XM, Meng HY, Yuan XL, Wang Y, Guo QY, Peng J, Wang AY, Lu SB. MicroRNAs' involvement in osteoarthritis and the prospects for treatments. Evidence-Based Complementary and Alternative Medicine. 2015 Oct 26;2015.

13. Endisha H, Rockel J, Jurisica I, Kapoor M. The complex landscape of microRNAs in articular cartilage: biology, pathology, and therapeutic targets. JCI insight. 2018 Sep 6;3(17).

14. Peffers MJ, Balaskas P, Smagul A. Osteoarthritis year in review 2017: genetics and epigenetics. Osteoarthritis and cartilage. 2018 Mar 1;26(3):304-11.

15. Dai L, Zhang X, Hu X, Zhou C, Ao Y. Silencing of microRNA-101 prevents IL-1 $\beta$-induced extracellular matrix degradation in chondrocytes. Arthritis research \& therapy. 2012 Dec;14(6):1-1.

16. Wang Q, Wang W, Zhang F, Deng Y, Long Z. NEAT1/miR-181c regulates osteopontin (OPN)-mediated synoviocyte proliferation in osteoarthritis. Journal of cellular biochemistry. 2017 Nov;118(11):377584.

17. Steck E, Boeuf S, Gabler J, Werth N, Schnatzer P, Diederichs S, Richter W. Regulation of H19 and its encoded microRNA-675 in osteoarthritis and under anabolic and catabolic in vitro conditions. Journal of molecular medicine. 2012 Oct;90(10):1185-95.

18. Kang Y, Song J, Kim D, Ahn C, Park S, Chun CH, Jin EJ. PCGEM1 stimulates proliferation of osteoarthritic synoviocytes by acting as a sponge for miR-770. Journal of Orthopaedic Research. 2016 Mar;34(3):412-8. 
19. Miyaki S, Sato T, Inoue A, Otsuki S, Ito Y, Yokoyama S, Kato Y, Takemoto F, Nakasa T, Yamashita S, Takada S. MicroRNA-140 plays dual roles in both cartilage development and homeostasis. Genes \& development. 2010 Jun 1;24(11):1173-85.

20. Yang CR, Shih KS, Liou JP, Wu YW, Hsieh IN, Lee HY, Lin TC, Wang JH. Denbinobin upregulates miR146a expression and attenuates IL-1 $\beta$-induced upregulation of ICAM-1 and VCAM- 1 expressions in osteoarthritis fibroblast-like synoviocytes. Journal of Molecular Medicine. 2014 Nov;92(11):1147-58.

21. Tardif G, Hum D, Pelletier JP, Duval N, Martel-Pelletier J. Regulation of the IGFBP-5 and MMP-13 genes by the microRNAs miR-140 and miR-27a in human osteoarthritic chondrocytes. BMC musculoskeletal disorders. 2009 Dec;10(1):1-1.

22. Yang F, Hu A, Zhao D, Guo L, Yang L, Wang B, Tian F, Liu B, Huang S, Xie H. An insertion/deletion polymorphism at the microRNA-122 binding site in the interleukin-1 a 3 '-untranslated region is associated with a risk for osteoarthritis. Molecular Medicine Reports. 2015 Oct 1;12(4):6199-206.

23. Li ZC, Han N, Li X, Li G, Liu YZ, Sun GX, Wang Y, Chen GT, Li GF. Decreased expression of microRNA130a correlates with TNF- $a$ in the development of osteoarthritis. International journal of clinical and experimental pathology. 2015;8(3):2555.

24. Lu X, Lin J, Jin J, Qian W, Weng X. Hsa-miR-15a exerts protective effects against osteoarthritis by targeting aggrecanase-2 (ADAMTS5) in human chondrocytes. International journal of molecular medicine. 2016 Feb 1;37(2):509-16.

25. Park SJ, Cheon EJ, Lee MH, Kim HA. MicroRNA-127-5p Regulates Matrix Metalloproteinase 13 Expression and Interleukin-1 $\beta$-Induced Catabolic Effects in Human Chondrocytes. Arthritis \& Rheumatism. 2013 Dec;65(12):3141-52.

26. Moldovan L, Batte KE, Trgovcich J, Wisler J, Marsh CB, Piper M. Methodological challenges in utilizing mi RNA s as circulating biomarkers. Journal of cellular and molecular medicine. 2014 Mar;18(3):371-90.

27. Buschmann D, Haberberger A, Kirchner B, Spornraft M, Riedmaier I, Schelling G, Pfaffl MW. Toward reliable biomarker signatures in the age of liquid biopsies-how to standardize the small RNA-Seq workflow. Nucleic Acids Research. 2016 Jul 27;44(13):5995-6018.

28. Murata K, Yoshitomi H, Tanida S, Ishikawa M, Nishitani K, Ito H, Nakamura T. Plasma and synovial fluid microRNAs as potential biomarkers of rheumatoid arthritis and osteoarthritis. Arthritis research \& therapy. 2010 Jun;12(3):1-4.

29. Li YH, Tavallaee G, Tokar T, Nakamura A, Sundararajan K, Weston A, Sharma A, Mahomed NN, Gandhi R, Jurisica I, Kapoor M. Identification of synovial fluid microRNA signature in knee osteoarthritis: differentiating early-and late-stage knee osteoarthritis. Osteoarthritis and Cartilage. 2016 Sep 1;24(9):1577-86.

30. Ntoumou E, Tzetis M, Braoudaki M, Lambrou G, Poulou M, Malizos K, Stefanou N, Anastasopoulou L, Tsezou A. Serum microRNA array analysis identifies miR-140-3p, miR-33b-3p, and miR-671-3p as potential osteoarthritis biomarkers involved in metabolic processes. Clinical epigenetics. 2017 Dec;9(1):1-5. 
31. Chen C, Chen H. Clinical Diagnosis Value of miR-29b-3p in Peripheral Blood Mononuclear Cells and Synovial Fluid Among Osteoarthritis Patients. Clinical Laboratory. 2019 Aug 1;65(8).

32. Zhang M, Liu L, Xiao T, Guo W. Detection of the expression level of miR-140 using realtime fluorescent quantitative PCR in knee synovial fluid of osteoarthritis patients. Zhong nan da xue xue bao. Yi xue ban= Journal of Central South University. Medical sciences. 2012 Dec 1;37(12):1210-4.

33. Kim MC, Lee SW, Ryu DY, Cui FJ, Bhak J, Kim Y. Identification and characterization of microRNAs in normal equine tissues by next generation sequencing. PloS one. 2014 Apr 2;9(4):e93662.

34. Pacholewska A, Mach N, Mata X, Vaiman A, Schibler L, Barrey E, Gerber V. Novel equine tissue miRNAs and breed-related miRNA expressed in serum. BMC genomics. 2016 Dec;17(1):1-5.

35. Barrey E, Bonnamy B, Barrey EJ, Mata X, Chaffaux S, Guerin G. Muscular microRNA expressions in healthy and myopathic horses suffering from polysaccharide storage myopathy or recurrent exertional rhabdomyolysis. Equine Veterinary Journal. 2010 Nov;42:303-10.

36. Desjardin C, Vaiman A, Mata X, Legendre R, Laubier J, Kennedy SP, Laloe D, Barrey E, Jacques C, Cribiu EP, Schibler L. Next-generation sequencing identifies equine cartilage and subchondral bone miRNAs and suggests their involvement in osteochondrosis physiopathology. BMC genomics. 2014 Dec;15(1):1-1.

37. da Costa Santos H, Hess T, Bruemmer J, Splan R. Possible role of MicroRNA in equine insulin resistance: a pilot study. Journal of equine veterinary science. 2018 Apr 1;63:74-9.

38. Castanheira C, Balaskas P, Falls C, Ashraf-Kharaz Y, Clegg P, Burke K, Fang Y, Dyer P, Welting TJ, Peffers MJ. Equine synovial fluid small non-coding RNA signatures in early osteoarthritis. BMC veterinary research. $2021 \mathrm{Dec} ; 17(1): 1-2$.

39. Chou CK, Chi SY, Huang CH, Chou FF, Huang CC, Liu RT, Kang HY. IRAK1, a target of miR-146b, reduces cell aggressiveness of human papillary thyroid carcinoma. The Journal of Clinical Endocrinology \& Metabolism. 2016 Nov 1;101(11):4357-66.

40. Li Y, Zhang H, Dong Y, Fan Y, Li Y, Zhao C. MiR-146b-5p functions as a suppressor miRNA and prognosis predictor in non-small cell lung cancer. Journal of Cancer. 2017;8(9):1704.

41. Liu X, Liu L, Zhang H, Shao Y, Chen Z, Feng X, Fang H, Zhao C, Pan J, Zhang H, Zeng C. MiR-146b accelerates osteoarthritis progression by targeting alpha-2-macroglobulin. Aging (Albany NY). 2019 Aug 31;11(16):6014.

42. Akhtar N, Rasheed Z, Ramamurthy S, Anbazhagan AN, Voss FR, Haqqi TM. MicroRNA-27b regulates the expression of matrix metalloproteinase 13 in human osteoarthritis chondrocytes. Arthritis \& Rheumatism. 2010 May;62(5):1361-71.

43. Chu CR, Williams AA, Coyle CH, Bowers ME. Early diagnosis to enable early treatment of preosteoarthritis. Arthritis research \& therapy. 2012 Jun;14(3):1-0.

44. Gässler, N., Reissner, C., Janzen, N., Kähnert, H. and Kleesiek, K., 1993. A high performance liquid chromatography method for the determination of glycosaminoglycans in human blood. Clinical Chemistry and Laboratory Medicine, 31(8), pp.503-512. 
45. Livak KJ, Schmittgen TD. Analysis of relative gene expression data using real-time quantitative PCR and the 2- $\triangle \triangle C T$ method. methods. 2001 Dec 1;25(4):402-8.

46. Reijman M, Hazes JM, Bierma-Zeinstra SM, Koes BW, Christgau S, Christiansen C, Uitterlinden AG, Pols HA. A new marker for osteoarthritis: cross-sectional and longitudinal approach. Arthritis \& Rheumatism: Official Journal of the American College of Rheumatology. 2004 Aug;50(8):2471-8.

47. Catterall JB, Stabler TV, Flannery CR, Kraus VB. Changes in serum and synovial fluid biomarkers after acute injury (NCT00332254). Arthritis research \& therapy. 2010 Dec;12(6):1-9.

48. Smedsrød B, Kjellen L, Pertoft H. Endocytosis and degradation of chondroitin sulphate by liver endothelial cells. Biochemical Journal. 1985 Jul 1;229(1):63-71.

49. Alwan WH, Carter SD, Bennett D, Edwards GB. Glycosaminoglycans in horses with osteoarthritis. Equine Veterinary Journal. 1991 Jan;23(1):44-7.

50. Wluka AE, Stuckey S, Snaddon J, Cicuttini FM. The determinants of change in tibial cartilage volume in osteoarthritic knees. Arthritis \& Rheumatism. 2002 Aug;46(8):2065-72.

51. Kulkarni P, Deshpande S, Koppikar S, Patil S, Ingale D, Harsulkar A. Glycosaminoglycan measured from synovial fluid serves as a useful indicator for progression of Osteoarthritis and complements Kellgren-Lawrence Score. BBA clinical. 2016 Dec 1;6:1-4.

52. Uesaka S, Nakayama Y, Shirai Y, Yoshihara K. Serum and synovial fluid levels of chondroitin sulfate in patients with osteoarthritis of the knee joint. Journal of Nippon Medical School. 2001;68(2):16570.

53. Baccarin RY, Rasera L, Machado TS, Michelacci YM. Relevance of synovial fluid chondroitin sulphate as a biomarker to monitor polo pony joints. Canadian journal of veterinary research. $2014 \mathrm{Jan}$ 1;78(1):50-60.

54. Tavallaee G, Rockel JS, Lively S, Kapoor M. MicroRNAs in synovial pathology associated with osteoarthritis. Frontiers in medicine. 2020 Aug 11;7:376.

55. Taganov KD, Boldin MP, Chang KJ, Baltimore D. NF-KB-dependent induction of microRNA miR-146, an inhibitor targeted to signaling proteins of innate immune responses. Proceedings of the National Academy of Sciences. 2006 Aug 15;103(33):12481-6.

56. Budd E, de Andrés MC, Sanchez-Elsner T, Oreffo RO. MiR-146b is down-regulated during the chondrogenic differentiation of human bone marrow derived skeletal stem cells and up-regulated in osteoarthritis. Scientific reports. 2017 Apr 24;7(1):1-1.

57. Okuhara A, Nakasa T, Shibuya H, Niimoto T, Adachi N, Deie M, Ochi M. Changes in microRNA expression in peripheral mononuclear cells according to the progression of osteoarthritis. Modern rheumatology. 2012 Jun 1;22(3):446-57.

58. Zhang X, Wang C, Zhao J, Xu J, Geng Y, Dai L, Huang Y, Fu SC, Dai K, Zhang X. miR-146a facilitates osteoarthritis by regulating cartilage homeostasis via targeting Camk2d and Ppp3r2. Cell Death \& Disease. 2017 Apr;8(4):e2734-.

59. Guan YJ, Li J, Yang XU, Du S, Ding J, Gao Y, Zhang Y, Yang K, Chen Q. Evidence that miR-146a attenuates aging-and trauma-induced osteoarthritis by inhibiting Notch1, IL-6, and IL-1 mediated 
catabolism. Aging cell. 2018 Jun;17(3):e12752.

60. Armstrong AP, Tometsko ME, Glaccum M, Sutherland CL, Cosman D, Dougall WC. A RANK/TRAF6dependent signal transduction pathway is essential for osteoclast cytoskeletal organization and resorptive function. Journal of Biological Chemistry. 2002 Nov 15;277(46):44347-56.

61. Jiang J, Zhang J, Wu C, Chen C, Bao G, Xu G, Xue P, Zhou Y, Sun Y, Cui Z. Knockdown of TRAF6 inhibits chondrocytes apoptosis and inflammation by suppressing the NF-KB pathway in lumbar facet joint osteoarthritis. Molecular and Cellular Biochemistry. 2021 Apr;476(4):1929-38.

62. Zhu LJ, Dai L, Zheng DH, Mo YQ, Ou-Yang X, Wei XN, Shen J, Zhang BY. Upregulation of tumor necrosis factor receptor-associated factor 6 correlated with synovitis severity in rheumatoid arthritis. Arthritis Research \& Therapy. 2012 Jun;14(3):1-3.

63. Li X, Gibson G, Kim JS, Kroin J, Xu S, Van Wijnen AJ, Im HJ. MicroRNA-146a is linked to pain-related pathophysiology of osteoarthritis. Gene. 2011 Jul 1;480(1-2):34-41.

64. West C, McDermott MF. Effects of microRNA-146a on the proliferation and apoptosis of human osteochondrocytes by targeting TRAF6 through the NF-KB signalling pathway. Bioscience reports. 2017 Aug 31;37(4).

65. Lv F, Huang Y, Lv W, Yang L, Li F, Fan J, Sun J. MicroRNA-146a ameliorates inflammation via TRAF6/NF-KB pathway in intervertebral disc cells. Medical Science Monitor: International mEdical Journal of Experimental and Clinical Research. 2017;23:659.

66. Miyaki S, Asahara H. Macro view of microRNA function in osteoarthritis. Nature Reviews Rheumatology. 2012 Sep;8(9):543-52.

67. Li X, Kroin JS, Kc R, Gibson G, Chen D, Corbett GT, Pahan K, Fayyaz S, Kim JS, Van Wijnen AJ, Suh J. Altered spinal microRNA-146a and the microRNA-183 cluster contribute to osteoarthritic pain in knee joints. Journal of Bone and Mineral Research. 2013 Dec;28(12):2512-22.

68. Wang JH, Shih KS, Wu YW, Wang AW, Yang CR. Histone deacetylase inhibitors increase microRNA146 a expression and enhance negative regulation of interleukin-1 $\beta$ signaling in osteoarthritis fibroblast-like synoviocytes. Osteoarthritis and cartilage. 2013 Dec 1;21(12):1987-96..

69. Zhang F, Wang J, Chu J, Yang C, Xiao H, Zhao C, Sun Z, Gao X, Chen G, Han Z, Zou W. MicroRNA$146 \mathrm{a}$ induced by hypoxia promotes chondrocyte autophagy through Bcl-2. Cellular Physiology and Biochemistry. 2015;37(4):1442-53.

70. Li J, Huang J, Dai L, Yu D, Chen Q, Zhang X, Dai K. miR-146a, an IL-1 $\beta$ responsive miRNA, induces vascular endothelial growth factor and chondrocyte apoptosis by targeting Smad4. Arthritis research \& therapy. 2012 Apr;14(2):1-3.

71. Jin L, Zhao J, Jing W, Yan S, Wang X, Xiao C, Ma B. Role of miR-146a in human chondrocyte apoptosis in response to mechanical pressure injury in vitro. International journal of molecular medicine. 2014 Aug 1;34(2):451-63.

72. Pillai RS. MicroRNA function: multiple mechanisms for a tiny RNA?. Rna. 2005 Dec 1;11(12):175361. 
73. Toegel S, Wu SQ, Otero M, Goldring MB, Leelapornpisid P, Chiari C, Kolb A, Unger FM, Windhager R, Viernstein $\mathrm{H}$. Caesalpinia sappan extract inhibits IL1 $\beta$-mediated overexpression of matrix metalloproteinases in human chondrocytes. Genes \& nutrition. 2012 Apr;7(2):307-18.

74. Li YH, Tavallaee G, Tokar T, Nakamura A, Sundararajan K, Weston A, Sharma A, Mahomed NN, Gandhi R, Jurisica I, Kapoor M. Identification of synovial fluid microRNA signature in knee osteoarthritis: differentiating early-and late-stage knee osteoarthritis. Osteoarthritis and Cartilage. 2016 Sep 1;24(9):1577-86.

75. Zhou Y, Li S, Chen P, Yang B, Yang J, Liu R, Li J, Xia D. MicroRNA-27b-3p inhibits apoptosis of chondrocyte in rheumatoid arthritis by targeting HIPK2. Artificial Cells, Nanomedicine, and Biotechnology. 2019 Dec 4;47(1):1766-71.

76. Song J, Lee M, Kim D, Han J, Chun CH, Jin EJ. MicroRNA-181b regulates articular chondrocytes differentiation and cartilage integrity. Biochemical and biophysical research communications. 2013 Feb 8;431(2):210-4.

77. Kostopoulou F, Malizos KN, Papathanasiou I, Tsezou A. MicroRNA-33a regulates cholesterol synthesis and cholesterol efflux-related genes in osteoarthritic chondrocytes. Arthritis research \& therapy. 2015 Dec;17(1):1-3.

78. Martinez-Sanchez A, Dudek KA, Murphy CL. Regulation of human chondrocyte function through direct inhibition of cartilage master regulator SOX9 by microRNA-145 (miRNA-145). Journal of Biological Chemistry. 2012 Jan 6;287(2):916-24.

79. Zhang G, Zhou Y, Su M, Yang X, Zeng B. Inhibition of microRNA-27b-3p relieves osteoarthritis pain via regulation of KDM4B-dependent DLX5. Biofactors. 2020 Sep;46(5):788-802.

80. Xu J, Lv S, Hou Y, Xu K, Sun D, Zheng Y, Zhang Z, Li X, Li Y, Chi G. miR-27b promotes type Il collagen expression by targetting peroxisome proliferator-activated receptor- $\gamma 2$ during rat articular chondrocyte differentiation. Bioscience Reports. 2018 Feb 28;38(1).

81. He Y, Siebuhr AS, Brandt-Hansen NU, Wang J, Su D, Zheng Q, Simonsen O, Petersen KK, ArendtNielsen L, Eskehave T, Hoeck HC. Type X collagen levels are elevated in serum from human osteoarthritis patients and associated with biomarkers of cartilage degradation and inflammation. BMC musculoskeletal disorders. 2014 Dec;15(1):1-0.

82. Fukui N, Ikeda Y, Ohnuki T, Tanaka N, Hikita A, Mitomi H, Mori T, Juji T, Katsuragawa Y, Yamamoto S, Sawabe M. Regional differences in chondrocyte metabolism in osteoarthritis: a detailed analysis by laser capture microdissection. Arthritis \& Rheumatism. 2008 Jan;58(1):154-63.

83. Kamekura S, Kawasaki Y, Hoshi K, Shimoaka T, Chikuda H, Maruyama Z, Komori T, Sato S, Takeda S, Karsenty G, Nakamura K. Contribution of runt-related transcription factor 2 to the pathogenesis of osteoarthritis in mice after induction of knee joint instability. Arthritis \& Rheumatism: Official Journal of the American College of Rheumatology. 2006 Aug;54(8):2462-70.

84. Appleton CT, McErlain DD, Pitelka V, Schwartz N, Bernier SM, Henry JL, Holdsworth DW, Beier F. Forced mobilization accelerates pathogenesis: characterization of a preclinical surgical model of osteoarthritis. Arthritis research \& therapy. 2007 Feb;9(1):1-5. 
85. Inada M, Wang Y, Byrne MH, Rahman MU, Miyaura C, López-Otín C, Krane SM. Critical roles for collagenase-3 (Mmp13) in development of growth plate cartilage and in endochondral ossification. Proceedings of the National Academy of Sciences. 2004 Dec 7;101(49):17192-7.

86. Wang Y, Middleton F, Horton JA, Reichel L, Farnum CE, Damron TA. Microarray analysis of proliferative and hypertrophic growth plate zones identifies differentiation markers and signal pathways. Bone. 2004 Dec 1;35(6):1273-93.

\section{Figures}

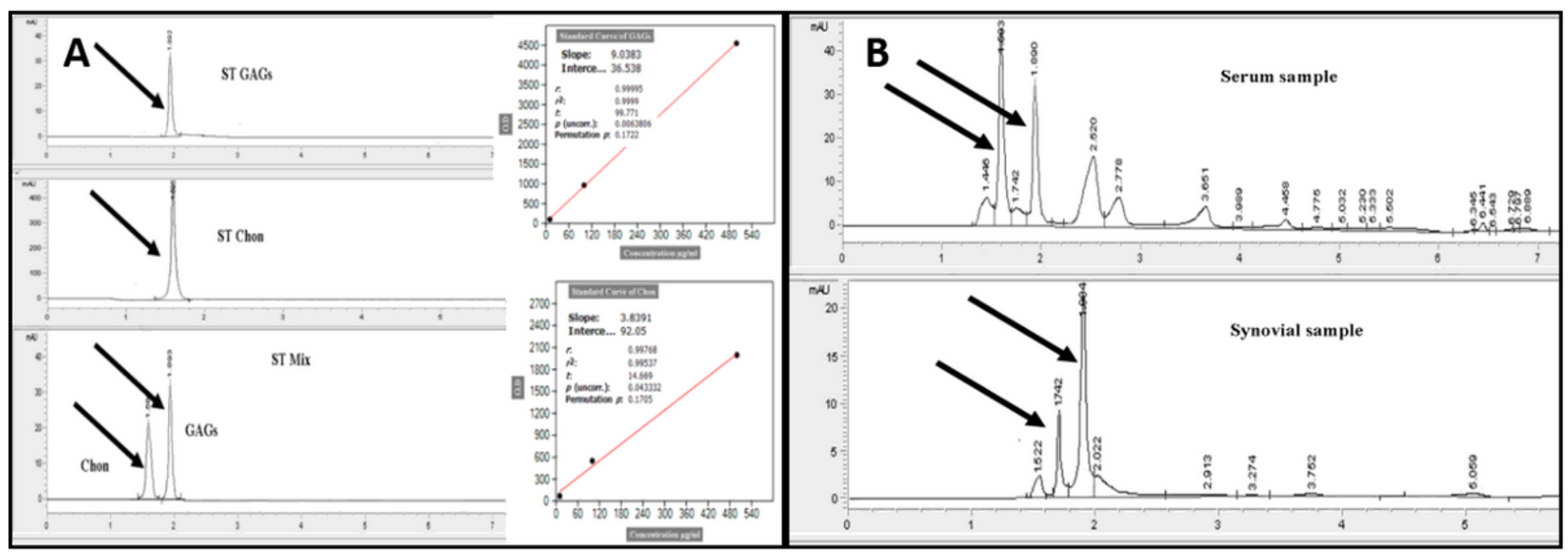

Figure 1

(A) Chromatograms for total GAGs and Chondroitin Sulphate standards. (B) chromatograms for total GAGs and chondroitin sulphate in serum and synovial fluid samples.

A

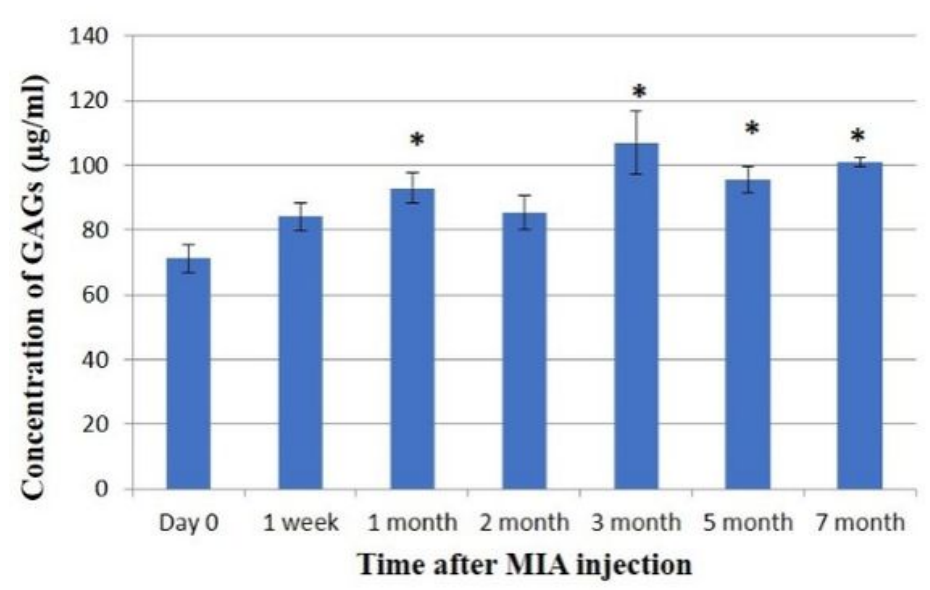

B

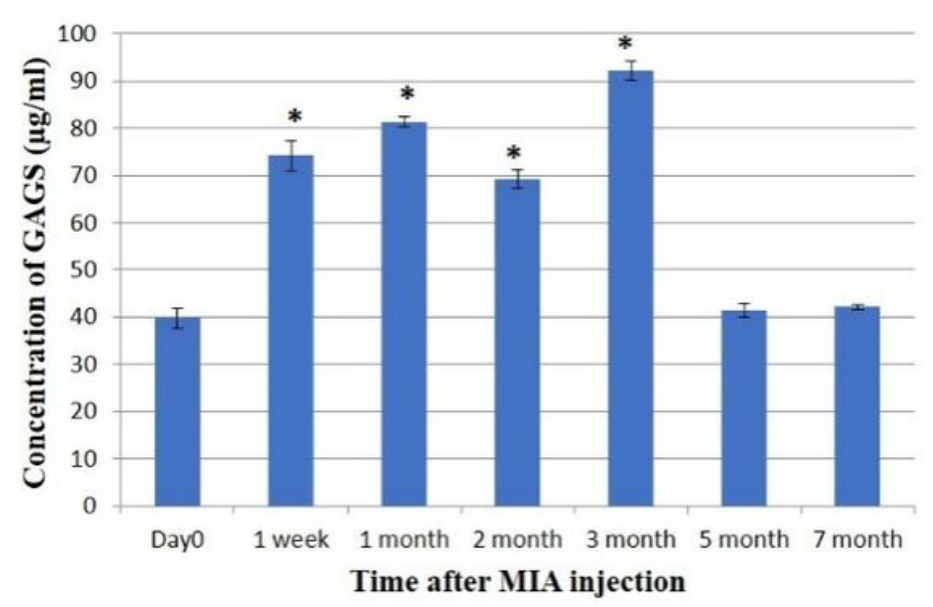

Figure 2 
The concentration of total GAGs $(\mu \mathrm{g} / \mathrm{ml})$ by HPLC. (A)The concentrations of total GAGs in serum samples. (B)The concentrations of total GAGs in synovial fluid samples. Data are represented as mean value \pm standard error $($ S.E. $)$ where $(n=3)$. $\left(^{*}\right)$ denotes a significant difference from control samples at day 0 at $p<0.05$.
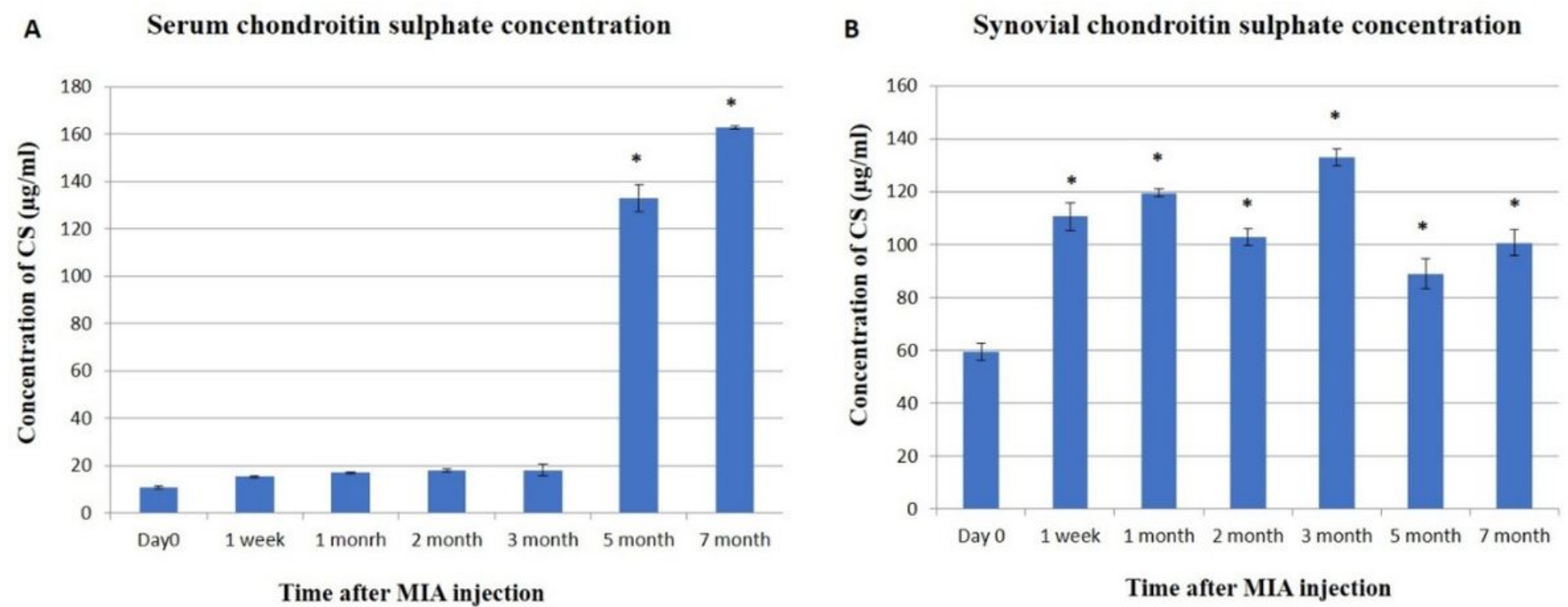

\section{Figure 3}

The concentration of chondroitin sulphate $(\mu \mathrm{g} / \mathrm{ml})$ by HPLC (A) The concentration of chondroitin sulphate in serum samples. (B) The concentration of chondroitin sulphate in synovial fluid samples. Data represented as mean value \pm standard error (S.E.) where $(n=3)$. $\left.{ }^{*}\right)$ denotes a significant difference from control samples at day 0 at $p<0.05$.

A

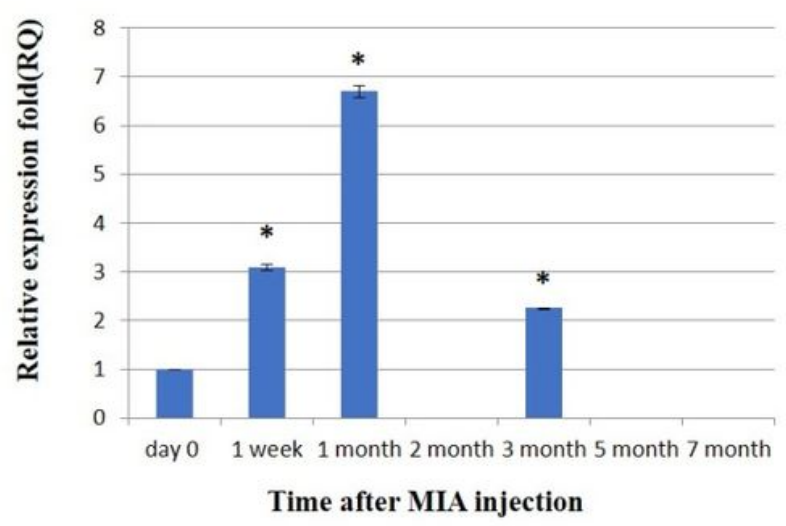

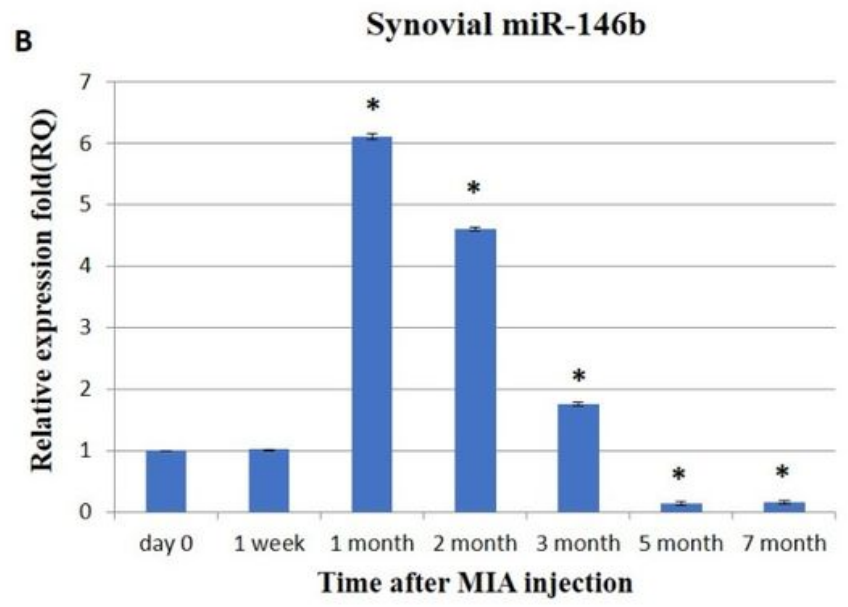

Figure 4 
The effect of MIA on the relative expression level of miR-146b gene: qRT-PCR results for miR-146b gene before MIA injection (Day 0) and post-MIA injection at 1 week, 1 month, 2 months, 3 months, 5 months, and 7 months in serum (A) and in synovial fluid (B). Data represented as mean value \pm standard error (S.E.) where $(n=3)$ of triplicate experiments. $\left.{ }^{*}\right)$ denotes a significant difference from control samples at day 0 at $p<0.05$.
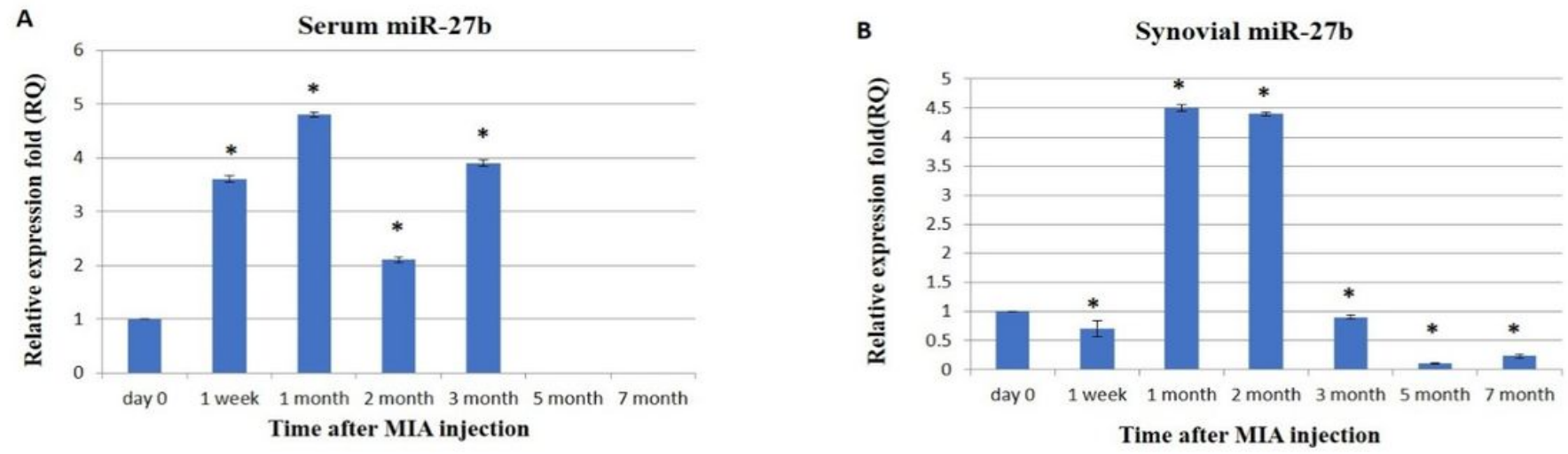

Figure 5

The effect of MIA on the relative expression level of miR-27b gene:qRT-PCR results for miR-27b before MIA injection (Day 0) and post-MIA injection at 1 week, 1 month, 2 months, 3 months, 5 months, and 7 months in serum(A) and in synovial fluid (B). Data represented as mean value \pm standard error (S.E.) where $(n=3)$ of triplicate experiments. $\left.{ }^{\star}\right)$ denotes a significant difference from control samples at day 0 at $\mathrm{p}<0.05$.
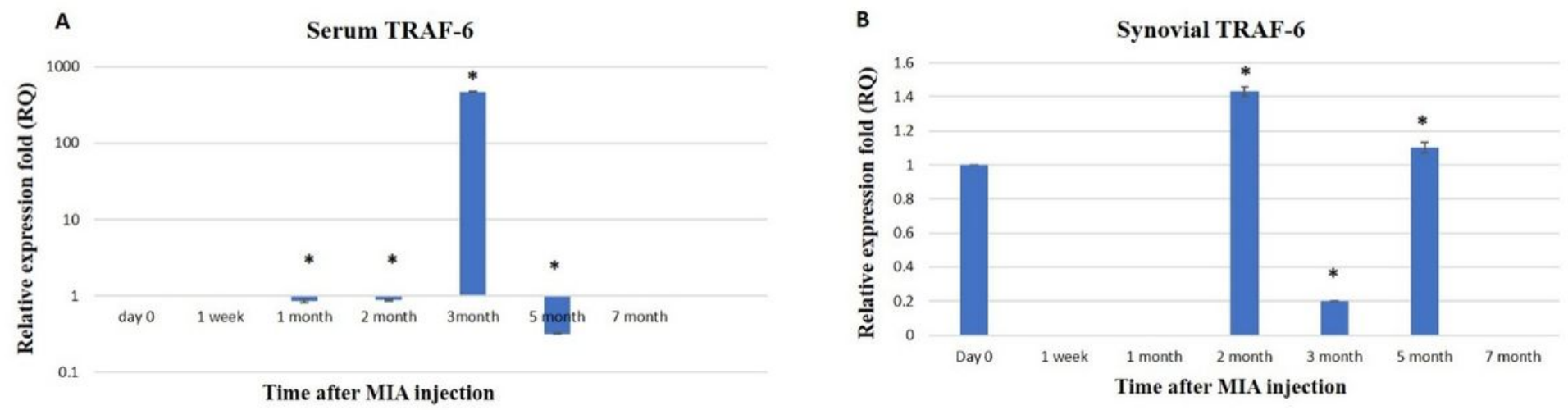

Figure 6

Graphical representation for the effect of MIA on the relative expression level of the TRAF- 6 gene. qRTPCR results before MIA injection (Day 0) and post-MIA injection at 1 week, 1 month, 2 months, 3 months, 5 months, and 7 months in serum(A) and in synovial fluid (B).Data represented as mean value \pm standard 
error (S.E.) where $(n=3)$ of triplicate experiments. $\left(^{*}\right)$ denotes a significant difference from control samples at day 0 at $p<0.05$.
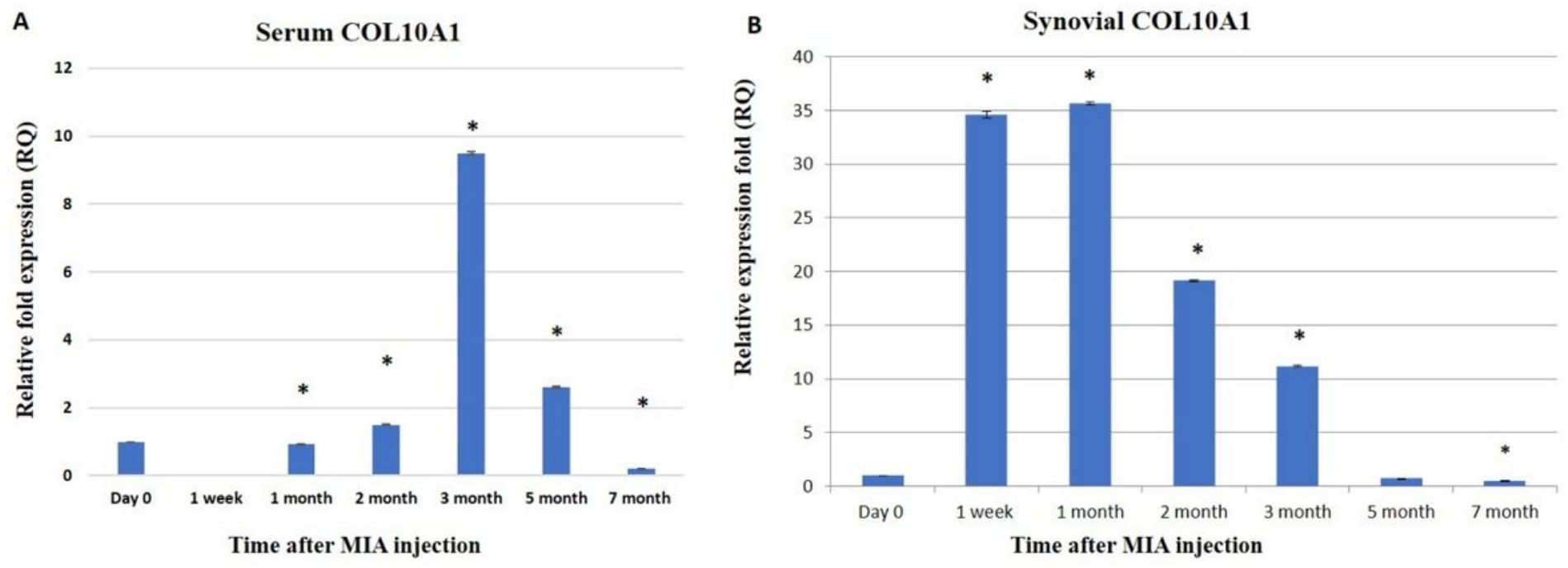

Figure 7

Graphical representation for the effect of MIA on the relative expression level of COL10A1 gene in serum. qRT-PCR results before MIA injection (Day 0) and post-MIA injection at 1 week, 1 month, 2 months, 3 months, 5 months, and 7 months in serum (A), and synovial fluid (B). Data represented as mean value \pm standard error (S.E.) where $(n=3)$ of triplicate experiments.. $\left.{ }^{*}\right)$ denotes a significant difference from control samples at day 0 at $p<0.05$. 